Int. J. Electrochem. Sci., 15 (2020) $6955-6968$

International Journal of

ELECTROCHEMICAL

SCIENCE

www.electrochemsci.org

\title{
Effect of Magnetic Fields on the Behavior of Iron Electrodeposition
}

\author{
Qiong Long ${ }^{1, *}$, Yunbo Zhong, ${ }^{2, *}$, Jianming $W u^{1}$ \\ ${ }^{1}$ Guizhou Key Laboratory for preparation of light metal materials, Guizhou Institute of Technology \\ Guiyang 550003, China \\ ${ }^{2}$ Shanghai key laboratory of modern metallurgy and material proceeding, shanghai university, \\ shanghai 200072, China \\ *E-mail: qiong12030@,163.com (Qiong Long); yunboz@,staff.shu.edu.cn (Yunbo Zhong)
}

doi: $10.20964 / 2020.07 .22$

Received: 7 March 2020 / Accepted: 16 April 2020 / Published: 10 June 2020

The behavior of iron deposition in a horizontal magnetic field was studied by electrochemical analysis. The influences of cathodic polarization curve, cyclic voltammetry, potentiostatic polarization and electrochemical impedance on the process of iron electrodeposition under magnetic field in different directions to current were investigated. The results showed that the mass transport process and charge transfer process were enhanced by applying magnetic fields.

Keywords: Electrodeposition; Magenetic field; Iron; Electrochemical analysis; MHD effect

\section{$\underline{\text { FULL TEXT }}$}

(C) 2020 The Authors. Published by ESG (www.electrochemsci.org). This article is an open access article distributed under the terms and conditions of the Creative Commons Attribution license (http://creativecommons.org/licenses/by/4.0/). 